\title{
Hyperthyroidism due to an intrathoracic tumour in a dog with test results suggesting hyperadrenocorticism
}

The elevated urinary corticoid/creatinine ratios of an 11-year-old Jack Russell terrier with polyuria were suppressible in a high-dose dexamethasone suppression test, which was suggestive of pituitary-dependent hyperadrenocorticism. The absence of physical and routine-laboratory changes compatible with hyperadrenocorticism and the relatively high plasma thyroxine concentration were the impetus for additional studies of thyroid and adrenocortical functions. A high plasma thyroxine concentration $(62 \mathrm{nmol} / \mathrm{l} ; 5.0 \mu \mathrm{g} / 100 \mathrm{ml}$ ) suggested the presence of hyperthyroidism. Radiography, ${ }^{99 \mathrm{~m}} \mathrm{TcO}_{4}{ }^{-}$scintigraphy, ultrasonography, computed tomography and cytology revealed a hyperfunctioning intrathoracic thyroid tumour. In the low-dose dexamethasone suppression test, the plasma cortisol concentration exceeded the reference value of $40 \mathrm{nmol} / \mathrm{l}(1.4 \mu \mathrm{g} / 100 \mathrm{ml})$ at eight hours after dexamethasone administration $(0.01 \mathrm{mg} / \mathrm{kg}$ intravenously), a test result compatible with hyperadrenocorticism. In conclusion, this report represents the first case of a dog with an autonomously hyperfunctioning thyroid tumour in the thorax. The elevated urinary corticoid excretion and the positive low-dose dexamethasone suppression test may be explained by alterations in cortisol metabolism, the stress of the hyperthyroid state or both.

\section{Q. E. M. Stassen, G. Voorhout*, E. Teske And A. RIJNBerk}

Journal of Small Animal Practice (2007) 48, 283-287

DOI: $10.1111 /$ j.1748-5827.2006.00233.x
Department of Clinical Sciences of Companion Animals and *Division of Diagnostic Imaging, Faculty of Veterinary Medicine, Utrecht University, The Netherlands

\section{INTRODUCTION}

Syndromes of hormone excess or deficiency often affect other endocrine systems. For example, in dogs, glucocorticoid excess leads to low plasma concentrations of thyroxine $\left(\mathrm{T}_{4}\right)$ and tri-iodothyronine (Kemppainen and others 1983). Glucocorticoids affect a variety of aspects of thyroid hormone secretion and metabolism, such as the production or clearance of $\mathrm{T}_{4}$, peripheral conversion of $\mathrm{T}_{4}$, renal clearance of iodide and the production or clearance of circulating thyroid- hormone-binding protein (Kaptein and others 1992, Dluhy 2000).

Conversely, from studies in experimental animals and in human beings, it is known that an excess of thyroid hormone causes accelerated cortisol clearance as well as changes in the pathways of cortisol degradation (Dluhy 2000). In cats with spontaneous hyperthyroidism due to thyroid adenomas, elevated urinary corticoid: creatinine ratios (UCCRs) have been reported. This has been ascribed to increased cortisol clearance and activation of the pituitary-adrenocortical axis (de Lange and others 2004).

Hyperthyroidism is rare in dogs. Thyroid tumours are often malignant, and in only 10 to 20 per cent of cases is there hypersecretion of thyroid hormone (Leav and others 1976, Mooney 2005). These tumours usually originate from eutopic thyroid glands, but they may also arise from ectopic thyroid tissue. About 50 per cent of healthy dogs have ectopic thyroid tissue (Godwin 1936, Blessing and Zaborsky 1966, Kameda 1972), as a result of thyroid tissue remaining at the level of the thyroglossal duct and/or descending with the heart during embryonic development.

Until now, there have been no reports on the adrenocortical function of dogs with hyperthyroidism. This case study reports on a polyuric dog with an ectopic hyperfunctioning thyroid tumour, with results of adrenocortical function studies that initially suggested the presence of pituitary-dependent hyperadrenocorticism.

\section{CASE HISTORY}

An 11-year-old, male neutered Jack Russell terrier, weighing $8 \mathrm{~kg}$, was examined by the local veterinarian for gradually worsening polyuria and polydipsia. The increased water intake had been noticed for the first time a few months earlier but had been ascribed to a change of diet. 
At that time, the dog was in good condition and physical examination had not revealed any abnormalities. Results of blood chemistry, haematology and urinalysis were unremarkable, except for a low specific urine gravity.

The plasma $\mathrm{T}_{4}$ concentration $(45 \mathrm{nmol} / \mathrm{l}$; $3.5 \mu \mathrm{g} / 100 \mathrm{ml}$ ) approached the upper limit of the reference range (19 to 46 $\mathrm{mmol} / \mathrm{l} ; 1.5$ to $3.6 \mu \mathrm{g} / 100 \mathrm{ml})$. The basal UCCR, measured in two urine samples collected on two consecutive mornings $\left(20 \times 10^{-6}\right.$ and $\left.14 \times 10^{-6}\right)$, exceeded the range found in 89 healthy dogs $(0.3$ to $8.3 \times 10^{-6}$; Van Vonderen and others 1997). Following the administration of three oral doses of $1 \mathrm{mg}$ dexamethasone at eight hour intervals, the UCCR had decreased to $4.2 \times 10^{-6}$. These findings were compatible with pituitary-dependent hyperadrenocorticism. However, there was some concern about this diagnosis because the dog had no physical signs of the disease and none of the usual biochemical changes, such as low $\mathrm{T}_{4}$ and elevated alkaline phosphatase (Teske and others 1989). The dog was referred to the Utrecht University Clinic for Companion Animals, the Netherlands.

At the time of admission, the polyuria had existed for about six months. The dog was still in good condition. Its appetite was good and there was no weight loss. The owner had noticed that the dog preferred cool places to lie down and panted frequently. The owner reported seeing abdominal distension only before micturition. The hair coat was unchanged, but there was less shedding. On physical examination, the pulse rate was high (160 bpm). In the neck area, no thyroid enlargement could be palpated.

Laboratory investigations revealed that the plasma concentration of alkaline phosphatase $(26 \mathrm{U} / \mathrm{l})$ was still within the reference range $(<73 \mathrm{U} / \mathrm{l})$. The basal UCCR had increased further $\left(33 \times 10^{-6}\right.$ and $\left.19 \times 10^{-6}\right)$. The elevated plasma $\mathrm{T}_{4}$ concentration $(62 \mathrm{nmol} / \mathrm{l})$ and the low plasma thyroid-stimulating hormone (TSH) concentration $(<0.02 \mu \mathrm{g} / \mathrm{l}$; reference $<0.60$ $\mu \mathrm{g} / \mathrm{l})$ were compatible with hyperthyroidism. It was assumed that the hyperthyroidism was due to an intrathoracic thyroid tumour, and that the elevated UCCR was secondary to the hyperthyroid state.
Additional investigations were performed to test this hypothesis.

Scintiscanning after intravenous admin-

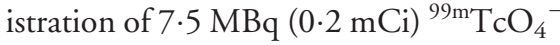
revealed uptake not only in areas of physiological iodide uptake, such as the parotid salivary gland and the gastric mucosa, but also in the cranial part of the thorax. There was almost no uptake by the thyroid glands (Fig 1). Thoracic radiographs visualised a large mass in the cranial mediastinum (Fig 2). On ultrasonography, the mass had mixed echogenicity with several small cysts. Cytological examination of ultrasound-guided fine-needle biopsies revealed epithelial glandular tissue, compatible with thyroid tumour tissue (Fig 3). On contrast-enhanced computed tomography $(\mathrm{CT})$, the mass was well circumscribed without signs of blood vessel invasion (Fig 4). There was no evidence of pulmonary metastases other than one very small nodule in the periphery of the right cranial lung lobe.

An intravenous low-dose dexamethasone suppression test (LDDST) was performed with blood collection for cortisol and adrenocorticotrophic hormone (ACTH) measurements at -15 minutes, immediately before and two, four, six and eight hours after intravenous administration of $0.01 \mathrm{mg} / \mathrm{kg}$ dexamethasone (Rijnberk and others 2001). As with the plasma ACTH concentration, the plasma cortisol concentration decreased to
$10 \mathrm{nmol} / \mathrm{l}(0.4 \mu \mathrm{g} / 100 \mathrm{ml})$ four hours after dexamethasone administration. At eight hours, the plasma cortisol concentration ( $44 \mathrm{nmol} / \mathrm{l} ; 1.6 \mu \mathrm{g} / 100 \mathrm{ml})$ exceeded the reference value of $40 \mathrm{nmol} / \mathrm{l}(1.4 \mu \mathrm{g} /$ $100 \mathrm{ml}$ ) (Fig 5). On contrast-enhanced CT, the pituitary gland was uniformly enhanced and not enlarged.

The owner declined the proposed surgical treatment, and the dog was euthanased two months later without postmortem examination.

\section{DISCUSSION}

There are several case reports of dogs with tumours originating from ectopic thyroid tissue in the thorax (Stephens and others 1982, Walsh and Diters 1984, Ware and others 1994, Constantino-Casas and others 1996). Ectopic thyroid tumours may also occur cranial to the thyroid gland. These tumours arise from thyroglossal duct remnants (Harkema and others 1984, Lantz \& Salisbury 1989) and may involve the base of the tongue. Similar to eutopic tumours, ectopic tumours often have malignant features (Leav and others 1976). The neoplastic transformation may be associated with (partially) defective thyroid hormone synthesis, leading to the release of iodinated albumin (Leav and others 1976, Rijnberk 1996).

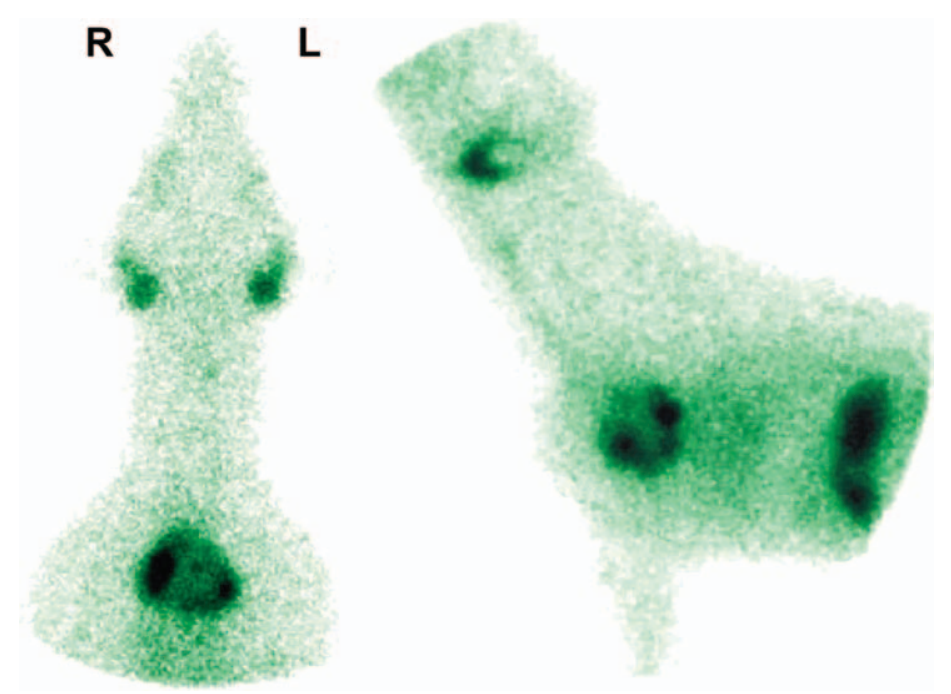

FIG 1. Scintiscan made 45 minutes after intravenous injection of ${ }^{99 m} \mathrm{TcO}_{4}{ }^{-}$. There is normal distribution of radioactivity in the salivary glands and gastric mucosa, but almost none in the thyroid glands. An increased uptake is seen in the cranial part of the thorax 

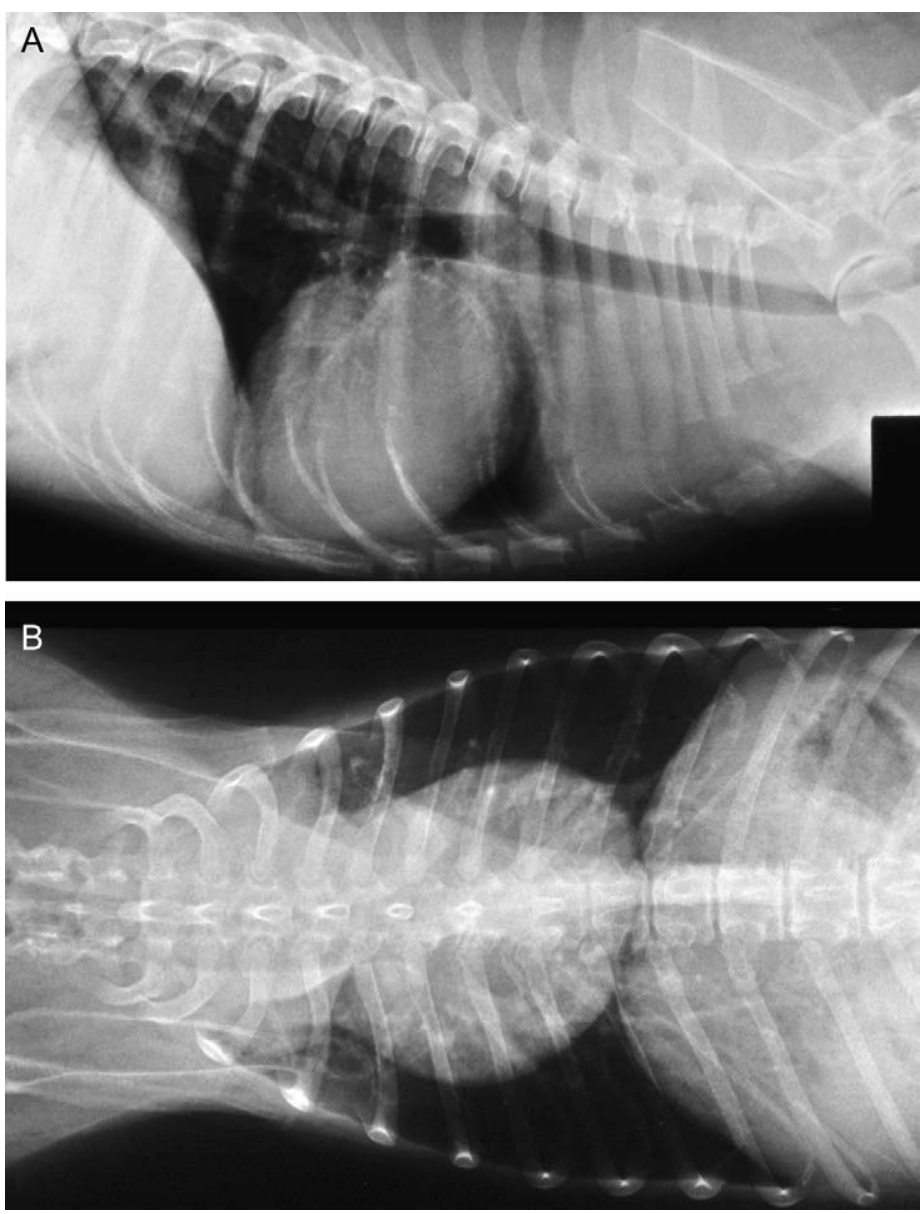

FIG 2. Lateral (A) and dorsoventral (B) radiographs of the thorax showing a mass in the cranial mediastinum

Like eutopic tumours, ectopic tumours may also secrete excessive amounts of thyroid hormones. To date, there is only

one report of a dog with hyperthyroidism due to an ectopic tumour. This tumour was located in the ventral portion of the

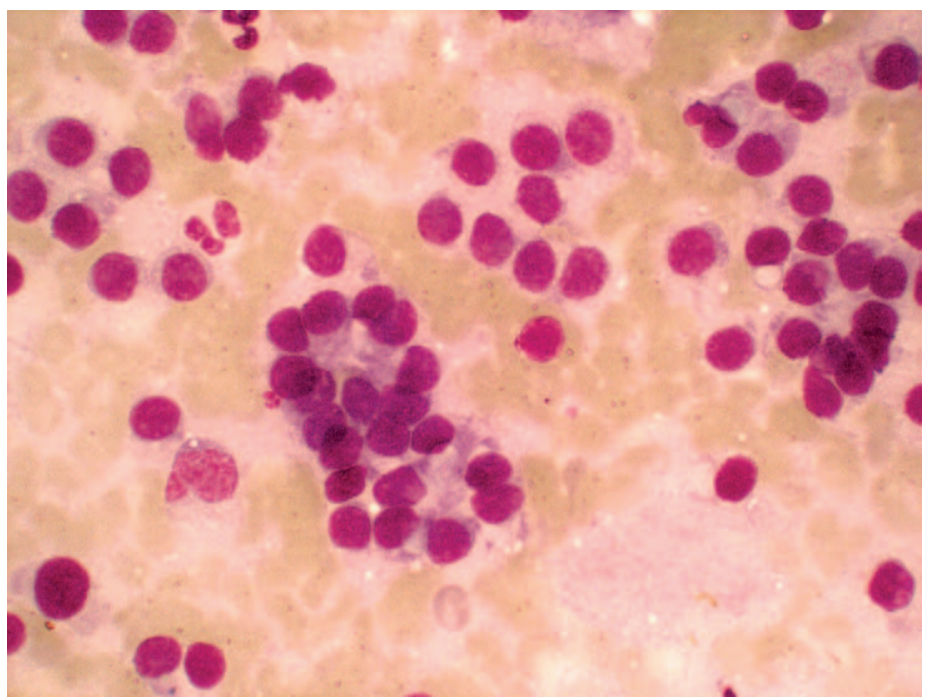

FIG 3. Cytology of a fine-needle biopsy of the thoracic mass with acinar arrangement of epithelial cells with a moderate amount of cytoplasm. May-Grünwald-Giemsa. $\times 500$ pharyngeal wall at the base of the tongue (Rijnberk 1981). Here, we report on an intrathoracic thyroid tumour causing hyperthyroidism. The autonomous and excessive thyroid hormone secretion suppressed the release of TSH, which led to almost no ${ }^{99} \mathrm{TcO}_{4}{ }^{-}$uptake in the eutopic thyroid tissue.

In this dog, the hyperthyroidism was associated with biochemical changes compatible with hyperadrenocorticism, that is, elevated UCCRs and positive LDDST. However, there were no physical or routine laboratory data suggesting hyperadrenocorticism. Also the diagnostic imaging of the pituitary gland did not reveal any changes. In the absence of indications for co-existent hyperadrenocorticism, other explanations for these findings were explored, which will be discussed in the order of (i) increased UCCRs and (ii) positive LDDST.

The increased UCCRs might be due to an increase in the rate of metabolic breakdown and transformation of cortisol. This has been documented in human beings and more recently in cats (Gallagher and others 1972, Linquette and others 1975, Larsen and Ingbar 1992, Dluhy 2000, de Lange and others 2004).

The rapid disposal of cortisol and its increased transformation into inactive metabolites that are unable to suppress the hypothalamus-pituitary system results in an increased pituitary release of ACTH and consequently increased cortisol secretion (Gallagher and others 1972). Thus, despite an enhanced breakdown and conversion of cortisol, plasma cortisol levels remain normal. The combination of increased breakdown/transformation and increased cortisol production results in elevated urinary concentrations of cortisol and cortisol metabolites (Hellman and others 1961, Dhuly 2000).

In the LDDST, the plasma cortisol concentration at eight hours after dexamethasone administration exceeded the reference value of $40 \mathrm{nmol} / \mathrm{l}(1.4 \mu \mathrm{g} /$ $100 \mathrm{ml}$ ) (Rijnberk and Mol 1997, Feldman and Nelson 2004). In principle, this abnormal test result may be a reflection of stress of disease, as has been previously suggested (Chastain and others 1986; Kaplan and others 1995; Gieger and others 2003). Another explanation, 


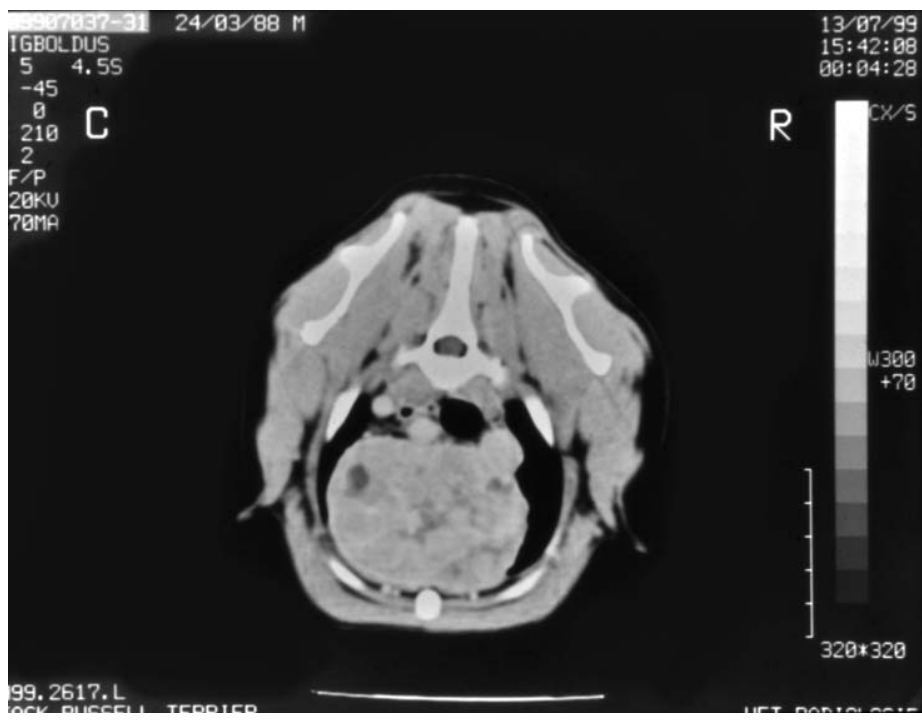

FIG 4. Contrast-enhanced computed tomography image of the cranial part of the thorax. The tumour is well circumscribed and there are no indications of invasion of blood vessels. The small radiolucent areas are cysts
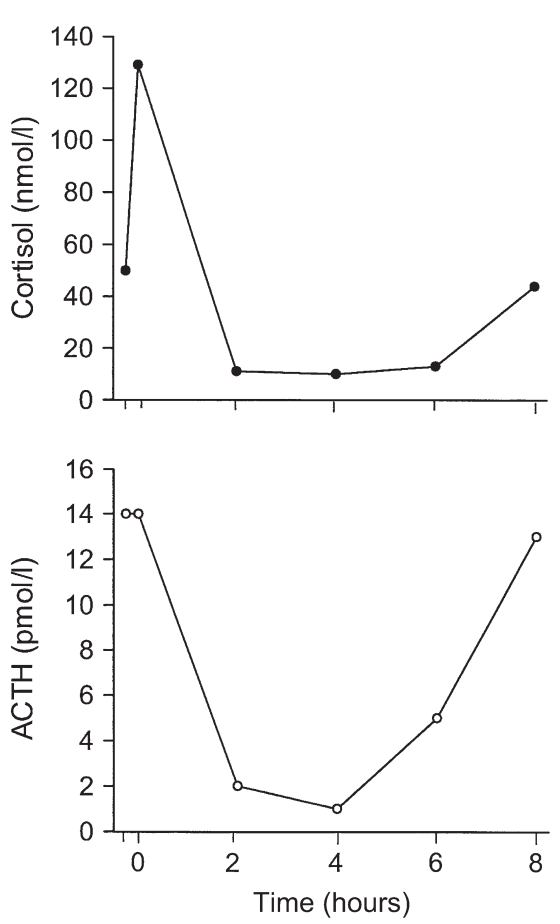

FIG 5. Plasma cortisol and adrenocorticotrophic hormone (ACTH) concentrations before and after intravenous administration (at time point 0 ) of $0.01 \mathrm{mg} / \mathrm{kg}$ dexamethasone

fitting in with the explanation of the elevated UCCRs, could be that the high cortisol concentrations at six and eight hours were the result of an escape from suppression, due to the above discussed increased clearance of glucocorticoids (including dexamethasone). A similar mechanism has been reported in dogswithhyperadrenocorticism (Lothrop and Oliver 1984).

\section{Conclusions}

This report represents the first case of a dog with an autonomously hyperfunctioning thyroid tumour in the thorax. The elevated corticoid excretion and the escape in the LDDST may be explained as being a consequence of hyperthyroidism-induced alterations in the metabolism and excretion of cortisol.

\section{Acknowledgements}

The authors gratefully acknowledge the assistance of Mrs Y. W. E. A. Pollak in performing the scintigraphy. The critical reading of the manuscript by Dr H. S. Kooistra is highly appreciated.

\section{References}

Blessing, M. H. \& ZABORSKY, F. (1966) Ueber den Nachweis von trathorakalem Schilddrüsengewebe des Hundes mit I 131 [ On the demonstration of intrathoracic thyroid tissue in dogs by means of I-131]. Frankfurter Zeitschrift für Pathologie 75, 14-24

Chastain, C. B., Franklin, R. T., Ganjam, V. K. \& Madsen, R. W. (1986) Evaluation of the hypothalamic pituitary-adrenal axis in clinically stressed dogs. Journal of the American Animal Hospital Association 22, 435-442

Constantino-Casas, F., Rodríguez-Martínez, H. A. \& Giutiérrez Díaz-ceballos, M. A. E. (1996) A case report and review: the gross, histological and immunohistochemical characteristics of a carcinoma of ectopic thyroid in a dog. British Veterinary Journal 152, 669-672 de Lange, M. S., Galac, S., Trip, M. R. J. \& Kooistra, H. S. (2004) High urinary corticoid/creatinine ratios in cats with hyperthyroidism. Journal of Veterinary Internal Medicine 18, 152-155

DLuhy, R. G. (2000) The adrenal cortex in thyrotoxicosis. In: Werner and Ingbar's The Thyroid. 8th edn. Eds L. E. Braverman and R. D. Utiger. Lippincott Williams \& Wilkins, Philadelphia, PA, USA. pp 637-641

Feldman, E. C. \& Nelson, R. W. (2004) Canine and Feline Endocrinology and Reproduction. $3^{\text {rd }}$ edn. W. B. Saunders, St. Louis, MO, USA. pp 252-357

Gallagher, T. F., Hellman, L., Finkelstein, J., Yoshida K., Weitzman, E. D., Roffwarg, H. D. \& Fukushima, D. K. (1972) Hyperthyroidism and cortisol secretion in man. Journal of Clinical Endocrinology and Metabolism 34, 919-927

Gieger, T. L., Feldman, E. C., Wallack, S. T. \& Dank, G. (2003) Lymphoma as a model for chronic illness: effects on adrenocortical function testing. Journal of Veterinary Internal Medicine 17, 154-157

Godwin, M. C. (1936) The early development of the thyroid gland in the dog with especial reference to the origin and position of accessory thyroid tissue within the thoracic cavity. Anatomical Record 66, 233-251

HaRkema, J. R., KING, R. R. \& HAHN, F. F. (1984) Carcinoma of thyroglossal duct cysts: a case report and review of the literature. Journal of the American Animal Hospital Association 20, 319-324

Hellman, L., Bradlow, H. L., Zumoff, B. \& Gallagher, T. F. (1961) The influence of thyroid hormone on hydrocortisone production and metabolism. Journal of Clinical Endocrinology and Metabolism 21, 1231-1247

KAMEDA, Y. (1972) The accessory thyroid glands of the dog around the intrapericardial aorta. Archiva Histologica Japonica 34, 375-391

Kaplan, A. J., Peterson, M. E. \& Kemppainen, R. J. (1995) Effects of disease on the results of diagnostic tests for use in detecting hyperadrenocorticism in dogs. Journal of the American Veterinary Medical Association 207, 445-451

Kaptein, E. M., Moore, G. E., Ferguson, D. C. \& Hoenig M. (1992) Effect of prednisone on thyroxine and 3, 5,3'-triiodothyronine metabolism in normal dogs. Endocrinology 130, 1669-1679. Erratum in Endocrinology (1992) 131, 1312

Kemppainen, R. J., Thompson, F. N., Lorenz, M. D., Munnell, J. F. \& Chakraborty, P. K. (1983) Effects of prednisone on thyroid and gonadal endocrine function in dogs. Journal of Endocrinology 96, 293-302

Lantz, G. C. \& Salisbury, S. K. (1989) Surgical excision of ectopic thyroid carcinoma involving the base of the tongue in dogs: three cases (1980-1987). Journal of the American Veterinary Medical Association 195, 1606-1608

LARSEN, P. R. \& IngBaR, S. H. (1992) The thyroid gland. In: William's Textbook of Endocrinology. 8th edn. Eds J. D. Wilson and D. W. Foster. W. B. Saunders, Philadelphia, PA, USA. pp 357-487

Leav, I., Schiller, A. L., Rijnberk, A., LegG, M. A. \& der Kinderen, P. J. (1976) Adenomas and carcinomas of the canine and feline thyroid. American Journal of Pathology 83, 61-122

Linouette, M., Lefebvre, J., Racadot, A. \& Cappoen, J.P. (1975) Proceeding: production rate, metabolic clearance rate and mean plasma concentration of cortisol in hyperthyroidism. Annals d'Endocrinologie 36, 35-36

Lothrop, C. D. Jr. \& Oliver, J. W. (1984) Diagnosis of canine Cushing's syndrome based on multiple steroid analysis and dexamethasone turnover kinetics. American Journal of Veterinary Research 45, 2304-2309

Mooney, C. T. (2005) Hyperthyroidism. In: Textbook of Veterinary Internal Medicine. 6th edn. Eds S. J. Ettinger and E. C. Feldman. Elsevier Saunders, St. Louis, MO, USA. pp 1544-1560

RIJNBERK, A. (1981) Thyroid neoplasia. In: Pathophysiology in Small Animal Surgery. Ed M. J. Bojrab. Lea \& Febiger, Philadelphia, PA, USA. pp 319-323 
RIJnBerk, A. (1996) Thyroids. In: Clinical Endocrinology of Dogs and Cats. Ed A. Rijnberk. Kluwer Academic Publishers, Dordrecht/Boston, the Netherlands/ USA. pp 35-59

RIJNBERK, A. \& MoL, J. A. (1997) Adrenocortical function. In: Clinical Biochemistry of Domestic Animals. 5th edn. Eds J. J. Kaneko, J. W. Harvey and M. L. Bruss. Academic Press, San Diego, CA USA. pp 553-570

Rijnberk, A., Kooistra, H. S., van Vonderen, I. K., Mol, J. A., Voorhout, G., van SluIJs, F. J., IJzer, J., van DEN INGH, T. S. G. A. M., Boer, P. \& BOer, W. H. (2001)
Aldosteronoma in a dog with polyuria as the leading symptom. Domestic Animal Endocrinology 20, 227-240

Stephens, L. C., Saunders, W. J. \& Jaenke, R. S. (1982) Ectopic thyroid carcinoma with metastases in a beagle dog. Veterinary Pathology 19, 669-675 Teske, E., Rothuizen, J., de Bruijne, J. J. \& Rijnberk, A. (1989) Corticoid-induced alkaline phosphatase iosenzyme in the diagnosis of canine hypercorticism. Veterinary Record 125, 12-14

Van Vonderen, I. K., Koolstra, H. S. \& Rijnberk, A. (1997). Intra- and interindividual variation in urine osmolality and urine specific gravity in healthy pet dogs of various ages. Journal of Veterinary Internal Medicine 11, 30-35

Walsh, K. M. \& Diters, R. W. (1984) Carcinoma of ectopic thyroid tissue. Journal of the American Animal Hospital Association 20, 665-668

Ware, W. A., Merkley, D. F. \& Riedesel, D. H. (1994) Intracardiac thyroid tumor in a dog: diagnosis and surgical removal. Journal of the American Animal Hospital Association 30, 20-23 